\title{
Breast Cancer Stem Cell Active Copper(II) Complexes with Naphthol Schiff Base and Polypyridyl Ligands
}

\author{
Joshua Northcote-Smith, Alice Johnson (1), Kuldip Singh, Fabrizio Ortu *(D) \\ and Kogularamanan Suntharalingam *(D) \\ School of Chemistry, University of Leicester, Leicester LE1 7RH, UK; jns7@leicester.ac.uk (J.N.-S.); \\ alice.johnson@leicester.ac.uk (A.J.); ks42@le.ac.uk (K.S.) \\ * Correspondence: fabrizio.ortu@leicester.ac.uk (F.O.); k.suntharalingam@leicester.ac.uk (K.S.); \\ Tel.: +44-(0)116-294-4670 (F.O.); +44-(0)116-294-4562 (K.S.)
}

\begin{abstract}
Breast cancer stem cells (CSCs) are a sub-population of tumour cells that can promote breast cancer relapse and metastasis. Current treatments are unable to completely remove breast CSCs, therefore it is essential to develop new chemotherapeutics that can remove breast CSCs at clinically compatible doses. Here we present the synthesis, characterisation, and anti-breast CSC properties of copper(II) complexes, $\left[\mathrm{Cu}\left(\mathbf{L}^{2}\right)(1,10-\right.$ phenanthroline $\left.)\right] \mathrm{PF}_{6}(2)$ and $\left[\mathrm{Cu}\left(\mathrm{L}^{3}\right)(1,10\right.$-phenanthroline $\left.)\right] \mathrm{PF}_{6}$ (3) comprising of a tridentate $(O, N, S)$ coordinated naphthol Schiff base ligand $\left(\mathbf{L}^{2}=(\mathrm{E})-1-(((2-\right.$ (methylthio)ethyl)imino)methyl)naphthalen-2-ol or $\mathbf{L}^{3}=(\mathrm{E})-1-(((2-($ ethylthio)ethyl)imino)methyl) naphthalen-2-ol and 1,10-phenanthroline. The copper(II) complexes (2 and 3) kill breast CSCs, cultured in monolayer and three-dimensional systems, in the micromolar range. Notably, 2 and 3 are more potent towards breast CSC mammospheres than salinomycin (up to 4.5-fold), an established anti-breast CSC agent. Further, cell-based studies indicate that $\mathbf{2}$ and $\mathbf{3}$ are readily taken up by breast CSCs and elevate intracellular reactive oxygen species (ROS) levels upon short exposure times $(0.5-1 \mathrm{~h})$. The latter is likely to be the underlying mechanism by which $\mathbf{2}$ and $\mathbf{3}$ induces breast CSC death.
\end{abstract}

Citation: Northcote-Smith, J.; Johnson, A.; Singh, K.; Ortu, F.; Suntharalingam, K. Breast Cancer Stem Cell Active Copper(II) Complexes with Naphthol Schiff Base and Polypyridyl Ligands. Inorganics 2021, 9, 5. https://doi.org/ 10.3390/inorganics 9010005

Received: 13 December 2020 Accepted: 28 December 2020 Published: 7 January 2021

Publisher's Note: MDPI stays neutral with regard to jurisdictional clai$\mathrm{ms}$ in published maps and institutional affiliations.

Copyright: (C) 2021 by the authors. Licensee MDPI, Basel, Switzerland. This article is an open access article distributed under the terms and conditions of the Creative Commons Attribution (CC BY) license (https:// creativecommons.org/licenses/by/ $4.0 /)$.

Keywords: metallopharmaceuticals; cancer stem cells; copper; bioinorganic chemistry; medicinal inorganic chemistry; reactive oxygen species

\section{Introduction}

Life-threatening diseases such as cancer and pathogenic infections impose a huge socioeconomic burden on humankind. Despite significant advances in cancer treatments annual cancer-related deaths within the European Union (EU) remain extremely high. Latest statistics indicate that cancer caused over 1.25 million deaths (accounting for $26 \%$ of all deaths) within EU28 countries in 2013 [1]. Amongst the various cancer types breast cancer caused the third most fatalities within EU28 countries (around 93,500 deaths). The economic impact of breast cancer across the EU, in terms of healthcare resources, productivity losses because of early death, lost working days, and informal care costs, amounts to around $€ 15.0$ billion [2]. Given these harrowing statistics, continuing to conduct basic research on new breast cancer medicines and therapies that could ultimately reduce mortality rates and lessen financial burden is of significant importance. Breast cancer relapse and metastasis, the leading cause of breast cancer associated deaths, is strongly linked to the existence of breast cancer stem cells (CSCs) [3,4]. Breast CSCs are a sub-set of breast cancer cells that have the intrinsic ability to differentiate, self-renew, and form secondary tumours $[5,6]$. Breast CSCs are known to evade current breast cancer therapy (including surgery, chemotherapy, and radiation), promote re-population of primary cancer sites, and potentially lead to fatal incidences of cancer relapse and metastasis $[7,8]$. Therefore it is vital that anti-breast chemotherapeutics possess the ability to remove breast CSCs at therapeutically significant doses. 
We and others have developed several breast CSC potent and selective metal complexes over the last six to seven years [9]. One of the most promising classes of anti-breast CSC agents reported thus far, are copper(II) complexes bearing polypyridyl and/or Schiff base ligands [10-13]. It should be noted that copper(II) complexes have been widely studied as anticancer agents (with limited studies focused on their anti-CSC potential), but none have been approved for clinic use [14,15]. The most advanced copper(II) complexes, called Casiopeinas, are currently in Phase I clinical trials [16-19]. The very latest studies suggest that Casiopeinas may be limited by dose-dependent cardiotoxicity [20], probably due to speciation. The breast CSC active copper(II) complexes developed by our group induce breast CSC death by generating intracellular reactive oxygen species (ROS), often activating the p38 and JNK stress pathways and caspase-dependent apoptosis [10-13]. The success of these copper(II) complexes against breast CSCs is thought to arise partly from the vulnerability of breast CSCs to subtle changes in their redox state [21,22]. Very recently we reported a copper(II) complex $\mathbf{1}$, containing a $O, N, S$-Schiff base ligand $\mathbf{L}^{\mathbf{1}}$, and 4,7-diphenyl-1,10-phenanthroline (see Supplementary Materials Figure S1 for chemical structures of $\mathbf{L}^{\mathbf{1}}$ and $\mathbf{1}$ ), capable of killing breast CSCs via cytotoxic and immunogenic mechanisms [23]. This was the first metal complex to induce immunogenic cell death (ICD) of breast CSCs and promote their engulfment by immune cells. This was an important step in our ongoing efforts to develop clinically viable anti-breast cancer drug candidates, as the removal of CSCs by immunological activation could serve as an effective method to eliminate residual CSCs after conventional CSC inactive treatments. In this study, we explore the breast CSC activity of structurally related copper(II) complexes ( $\mathbf{2}$ and $\mathbf{3}$ ) where the Schiff base ligand $\mathbf{L}^{\mathbf{1}}$ in $\mathbf{1}$ has been modified. Specifically a naphthalene moiety was incorporated into the Schiff base ligand scaffold to yield (E)-1-(((2(methylthio)ethyl)imino)methyl)naphthalen-2-ol $\left(\mathbf{L}^{2}\right)$ which was used to prepare the corresponding copper(II) complex with 1,10-phenanthroline, $\left[\mathrm{Cu}\left(\mathbf{L}^{2}\right)(1,10\right.$-phenanthroline $\left.)\right] \mathrm{PF}_{6}$ (2) (Scheme 1). Furthermore, the methyl group on the sulphur atom in $\mathbf{L}^{2}$ was replaced with an ethyl group to yield (E)-1-((2-(ethylthio)ethyl)imino)methyl)naphthalen-2-ol $\left(\mathbf{L}^{3}\right)$, which was subsequently used to prepare the corresponding copper(II) complex with 1,10-phenanthroline, $\left[\mathrm{Cu}\left(\mathrm{L}^{3}\right)(1,10\right.$-phenanthroline) $] \mathrm{PF}_{6}$ (3) (Scheme 1). These structural modifications were expected to modulate breast CSC uptake and intracellular ROS generation. Herein we report the synthesis, characterisation, and anti-breast CSC properties of the copper(II) complexes, $\left[\mathrm{Cu}\left(\mathbf{L}^{2}\right)(1,10\right.$-phenanthroline $\left.)\right] \mathrm{PF}_{6}(2)$ and $\left[\mathrm{Cu}\left(\mathbf{L}^{3}\right)(1,10-\right.$ phenanthroline) $\mathrm{PF}_{6}(3)$.

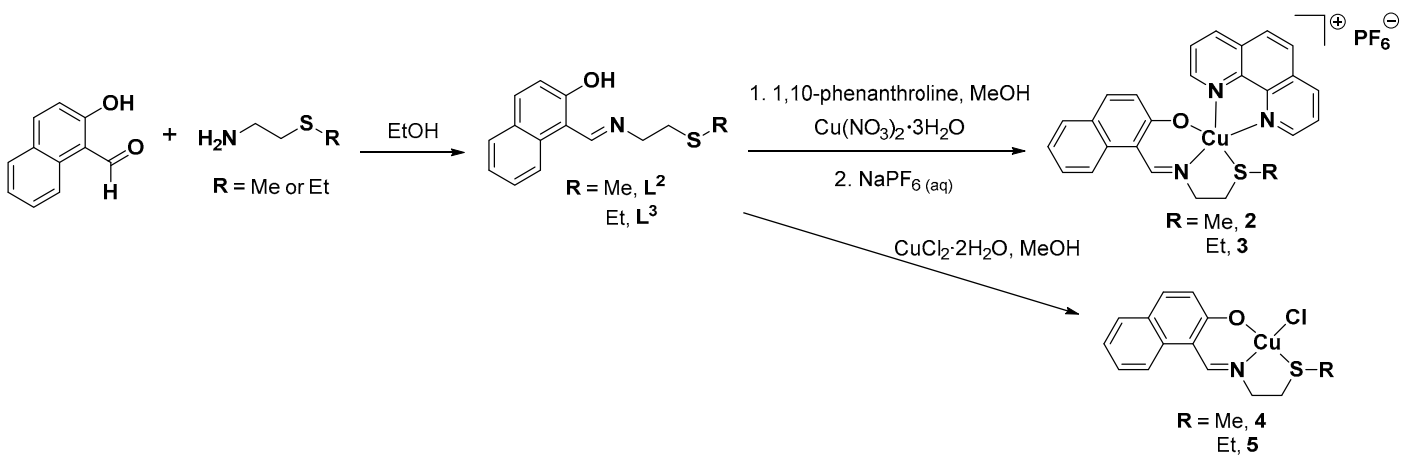

Scheme 1. The reaction scheme for the preparation of the naphthol Schiff base ligands, $\mathbf{L}^{2}$ and $\mathbf{L}^{3}$ and the corresponding copper(II) complexes 2-5.

\section{Results and Discussion}

\subsection{Synthesis and Characterisation of the Ligands and Copper(II) Complexes}

The copper(II) complexes $\left[\mathrm{Cu}\left(\mathbf{L}^{2}\right)(1,10\right.$-phenanthroline $\left.)\right] \mathrm{PF}_{6}(2)$ and $\left[\mathrm{Cu}\left(\mathbf{L}^{3}\right)(1,10\right.$ phenanthroline) $\mathrm{PF}_{6}$ (3) were prepared as outlined in Scheme 1. The naphthol Schiff 
base ligands, (E)-1-(((2-(methylthio)ethyl)imino)methyl)naphthalen-2-ol ( $\left.\mathbf{L}^{2}\right)$ and (E)-1-(((2(ethylthio)ethyl)imino)methyl)naphthalen-2-ol $\left(\mathbf{L}^{3}\right)$ were prepared by reacting equimolar amounts of 2-(methylthio)ethylamine or 2-(ethylthio)ethylamine with 2-hydroxy-1naphthaldehyde in ethanol for $16 \mathrm{~h}$. The ligands, $\mathbf{L}^{2}$ and $\mathbf{L}^{3}$ were isolated in excellent yields $(96-100 \%)$ as orange solids and fully characterised by ${ }^{1} \mathrm{H}$ and ${ }^{13} \mathrm{C}$ NMR, infrared (IR) spectroscopy, high-resolution ESI mass spectrometry, and elemental analysis (see Section 3 and Figures S2-S8). Characteristic signals at 9.10-9.11 ppm and 177.84-177.85 ppm in the ${ }^{1} \mathrm{H}$ and ${ }^{13} \mathrm{C}$ NMR spectra for $\mathbf{L}^{2}$ and $\mathbf{L}^{3}$ respectively confirmed formation of the imine functionality. Disappearance for the aldehyde peak at $10.82 \mathrm{ppm}$ and 193.33 ppm in the ${ }^{1} \mathrm{H}$ and ${ }^{13} \mathrm{C}$ NMR spectra corresponding to the 2-hydroxy-1-naphthaldehyde starting material established full conversion to the imine product (Figures S9 and S10). Further, the IR spectra of $\mathbf{L}^{2}$ and $\mathbf{L}^{3}$ exhibited bands at $1610-1616 \mathrm{~cm}^{-1}$ corresponding to the $\mathrm{C}=\mathrm{N}_{\text {imine }}$ stretch. The purity of $\mathbf{L}^{2}$ and $\mathbf{L}^{3}$ was confirmed by elemental analysis (see Section 3). The copper(II) complexes, 2 and 3 were prepared by reacting equimolar amounts of 1,10-phenanthroline with copper(II) nitrate hydrate in methanol, followed by the addition of the Schiff base ligand, $\mathbf{L}^{2}$ or $\mathbf{L}^{3}$ and excess sodium hexafluorophosphate. The complexes were isolated in reasonable yields (45-69\%) as (dark) green solids and fully characterised by high-resolution ESI mass spectrometry, IR spectroscopy, and elemental analysis (see Section 3 and Figures S8, S11 and S12). Distinctive molecular ion peaks corresponding to $\mathbf{2}$ and $\mathbf{3}$ with the appropriate isotopic pattern were observed in the HR ESI-MS $\left(\mathrm{m} / \mathrm{z}=487.0775\left[2-\mathrm{PF}_{6}\right]^{+} ; 501.0936\left[3-\mathrm{PF}_{6}\right]^{+} ;\right.$Figures S11 and S12). The IR spectra for 2 and 3 displayed $C=N_{\text {imine }}$ bands between $1616-1618 \mathrm{~cm}^{-1}$ indicating the presence of the imine functionality associated to $\mathbf{L}^{2}$ and $\mathbf{L}^{3}$ (Figure $\mathrm{S} 8$ ). Furthermore, the IR spectra for $\mathbf{2}$ and $\mathbf{3}$ did not display a broad O-H stretch (Figure S8), supporting the tridentate complexation of $\mathbf{L}^{2}$ and $\mathbf{L}^{3}$ to the copper centre as depicted in Scheme 1. The purity of $\mathbf{2}$ and 3 was established by elemental analysis (see Section 3). $\left[\mathrm{Cu}\left(\mathbf{L}^{2}\right) \mathrm{Cl}\right](\mathbf{4})$ and $\left[\mathrm{Cu}\left(\mathbf{L}^{3}\right) \mathrm{Cl}\right]$ (5) were also prepared to serve as control compounds (as outlined in Scheme 1)—copper(II) complexes without 1,10-phenanthroline. The synthetic protocol and full characterisation of 4 and 5 (high-resolution ESI mass spectrometry, IR spectroscopy, and elemental analysis) is reported in the Section 3 (Figures S8, S13 and S14).

Single (dark green needle-like) crystals of $\mathbf{2}$ and $\mathbf{3}$ suitable for X-ray diffraction studies were obtained by slow evaporation of an acetone solution of 2 and by vapour diffusion of diethyl ether into an acetonitrile solution of 3 (CCDC 2046679-2046680, Figure 1, Table S1). Selected bond distances and angles are presented in Tables S2 and S3. The cationic component of 2 exhibits a distorted trigonal bipyramidal geometry with the copper(II) centre coordinated to $\mathrm{L}^{2}$ in a tridentate manner (via the $\mathrm{O}, \mathrm{N}$, and $\mathrm{S}$ atoms) and 1,10phenanthroline in a bidentate manner. Within the CuNOS equatorial plane, the $\mathrm{O}(1)-\mathrm{Cu}-$ $\mathrm{S}(1), \mathrm{O}(1)-\mathrm{Cu}-\mathrm{N}(2)$, and $\mathrm{N}(2)-\mathrm{Cu}-\mathrm{S}(1)$ bond angles average to $119.90(15)^{\circ}$, and the axial $\mathrm{N}(1)-\mathrm{Cu}-\mathrm{N}(3)$ angle is $177.78(12)$. This is consistent with a distorted trigonal bipyramidal geometry $\left(\tau_{5}=0.96\right)$ (Figure 1$)$. The cationic component of 3 also adopts a distorted trigonal bipyramidal geometry $\left(\tau_{5}=0.94\right)$, however, the structure is disordered due to the flexibility of the thioethyl moiety in $\mathbf{L}^{3}$ (Figure 1). Alike 2, the copper(II) centre in $\mathbf{3}$ binds to $\mathbf{L}^{3}$ in a tridentate manner (via the $\mathrm{O}, \mathrm{N}$, and $\mathrm{S}$ atoms) and 1,10-phenanthroline in a bidentate manner. Overall, the $\mathrm{Cu}-\mathrm{N}_{\text {imine, }}, \mathrm{Cu}-\mathrm{N}_{\text {polypyridyl }}, \mathrm{Cu}-\mathrm{S}$, and $\mathrm{Cu}-\mathrm{O}$ bond lengths observed for $\mathbf{2}$ and $\mathbf{3}$ are consistent with bond parameters reported for related 5-coordinate copper(II) complexes (Tables S2 and S3) [23-25].

\subsection{Lipophilicity and Solution Stability of the Copper(II) Complexes}

It is important to understand the lipophilicity of compounds intended for medical applications as this directly affects aqueous solubility, absorption, distribution, and toxicity [26]. The ability of a given compound to partition between octanol and water (P) is a good indicator of their inherent lipophilicity. The lipophilicity of $2-5$ was gauged in this manner. As shown in Table S4, the experimentally determined LogP values for 2-5 were between $-0.63 \pm 0.03$ and $0.34 \pm 0.03$. These values suggest that $\mathbf{2 - 5}$ are amphiphilic and thus 
should be internalised easily by cells and be partially soluble in water. To probe the stability of $\mathbf{2}$ and $\mathbf{4}$, taken as demonstrative compounds within the copper(II) complex series, UV-Vis spectroscopy studies were performed in physiologically relevant solutions. The absorbance of 2 and $4(50 \mu \mathrm{M})$ in PBS:DMSO (200:1) altered significantly over the course of $24 \mathrm{~h}$ at $37^{\circ} \mathrm{C}$ upon addition of ascorbic acid (10 equivalents), a cellular reductant (Figures S15 and S16). For complex 2, the absorbance of the $\pi-\pi^{*}$ and MLCT bands decreased by up to $54 \%$ after $24 \mathrm{~h}$ whereas for complex 4 the bands completely disappeared in the same timeframe, suggesting that the 1,10-phenanthroline ligand in 2 provides some protection against ascorbic acid reduction-mediated instability. It is worth pointing out that the reaction between 2 or 4 and ascorbic acid (mostly likely a reduction reaction) is time-dependent and may be proceeding via many reaction pathways (Figures S15 and S16). The addition of bathocuproine disulfonate (BCS, 2 equivalents), which is a strong and selective copper(I) chelator, to 2 and $4(50 \mu \mathrm{M})$ and ascorbic acid (10 equivalents) in PBS:DMSO (200:1) produced a distinct absorbance band at $480 \mathrm{~nm}$ corresponding to $\left[\mathrm{Cu}^{\mathrm{I}}(\mathrm{BCS})_{2}\right]^{3-}$ (Figures $\mathrm{S} 17$ and S18). This clearly shows that the copper(II) centre in $\mathbf{2}$ and $\mathbf{4}$ is reduced to copper(I) in the presence of ascorbic acid. Collectively, analysis of the UV-Vis spectroscopy data indicates that $\mathbf{2}$ and 4 are reduced from the copper(II) form to the copper(I) form under biologically reducing conditions. Before beginning cell-based studies, UV-Vis spectroscopy was used to probe the stability of $\mathbf{2}$ and $\mathbf{4}$ in mammary epithelial cell growth medium (MEGM) over the course of $24 \mathrm{~h}$ at $37^{\circ} \mathrm{C}$ (Figures S19 and S20). Both complexes were deemed to be reasonably stable under these condition, with the 1,10-phenanthroline-containing complex 2 displaying greater stability than 4 .
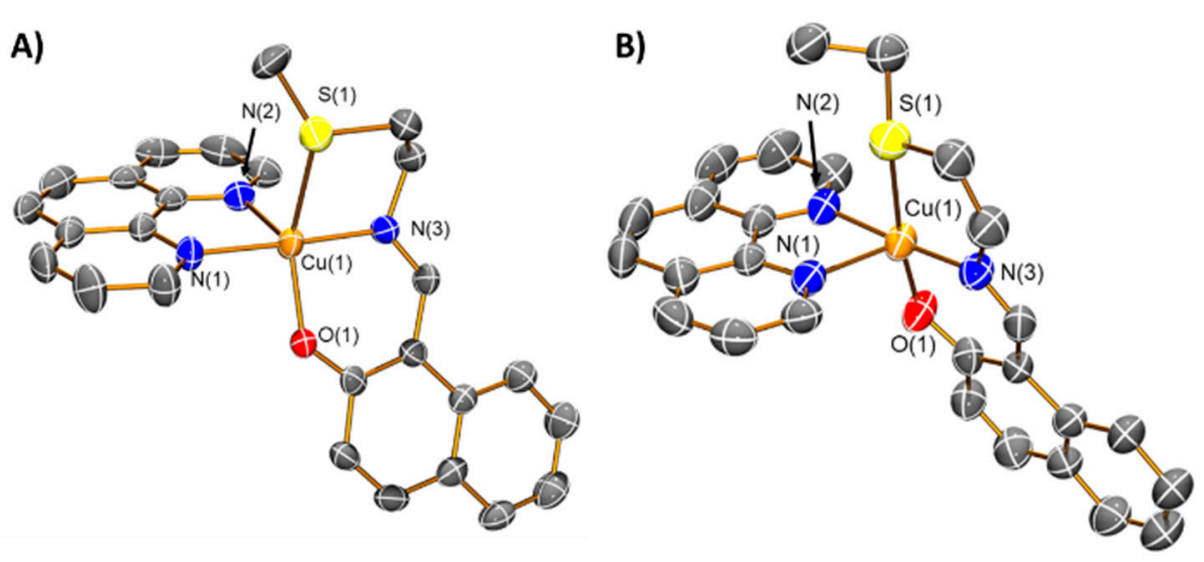

Figure 1. X-ray structures of the copper(II) complexes $\mathbf{2}$ (A) and $\mathbf{3}$ (B) comprising of $\mathbf{L}^{2}$ or $\mathbf{L}^{3}$ and 1,10-phenanthroline. Ellipsoids are shown at 50\% probability. $\mathrm{C}$ in grey, $\mathrm{N}$ in dark blue, $\mathrm{S}$ in yellow, $\mathrm{O}$ in red, and $\mathrm{Cu}$ in orange. $\mathrm{H}$ atoms, disorder components, and the hexafluorophosphate counter anion have been omitted for clarity.

\subsection{In Vitro Cytotoxicity of the Copper(II) Complexes}

The monolayer cytotoxicity of $\mathbf{2}-\mathbf{5}$ towards bulk breast cancer cells (HMLER) and breast CSCs (HMLER-shEcad) was assessed using the colorimetric MTT assay. IC $_{50}$ values were determined from dose-response curves (Figures S21-S24) and are summarized in Table 1. The copper(II) complexes, 2-5 all displayed micromolar potency towards HMLER and HMLERshEcad cells. The mono-cationic 1,10-phenanthroline-containing complexes $\mathbf{2}$ and $\mathbf{3}$ exhibited significantly $(p<0.05)$ higher potency towards HMLER and HMLER-shEcad cells than the corresponding neutral chloride-containing complexes 4 and 5 (Table 1). This suggests that the presence of the 1,10-phenanthroline ligand in 2 and 3 enhances their breast CSC toxicity. Complexes 2 and 3 displayed similar potency for breast CSCs and bulk breast cancer cells, whereas $\mathbf{4}$ and $\mathbf{5}$ displayed greater potency for bulk breast cancer cells over breast CSCs. The former suggests that $\mathbf{2}$ and $\mathbf{3}$ have the potential to kill entire heterogeneous breast cancer cell populations (consisting of bulk breast cancer cells and breast CSCs) with a single micromolar 
dose. The similarity in $\mathrm{IC}_{50}$ values of $\mathbf{2}$ and $\mathbf{3}$ (towards HMLER and HMLER-shEcad cells) indicates that modification of the thioalkyl moiety within the Schiff base ligand, from a methyl group to an ethyl group, had little effect on potency. Notably, the potency of 2 and 3 for CSC-enriched HMLER-shEcad cells was slightly greater than that of salinomycin, an established clinically-tested anti-breast CSC agent [10]. Control cytotoxicity studies showed that the potency of the free naphthol Schiff base ligands $\mathbf{L}^{2}$ and $\mathbf{L}^{3}, \mathrm{CuCl}_{2} \cdot 2 \mathrm{H}_{2} \mathrm{O}$ [27], and dichloro(1,10-phenanthroline)copper(II) [10] towards HMLER and HMLER-shEcad cells were all significantly lower $(p<0.05)$ than 2 and 3 (Table 1, Figures S25 and S26). This suggests that the cytotoxicity of $\mathbf{2}$ and $\mathbf{3}$ towards bulk breast cancer cells and breast CSCs is likely to result from the intact cellular entry of the copper(II) complexes, which allows for the synergistic co-delivery of all the complex components.

Table 1. $\mathrm{IC}_{50}$ values of the copper(II) complexes $\mathbf{2}-\mathbf{5}$, the naphthol Schiff base ligands $\mathbf{L}^{2}$ and $\mathrm{L}^{3}$, salinomycin, $\mathrm{CuCl}_{2} \cdot 2 \mathrm{H}_{2} \mathrm{O}$, and dichloro(1,10-phenanthroline)copper(II) against HMLER and HMLER-shEcad cells and HMLER-shEcad mammospheres determined after $72 \mathrm{~h}$ or $120 \mathrm{~h}$ incubation (mean of three independent experiments $\pm \mathrm{SD}$ ).

\begin{tabular}{|c|c|c|c|}
\hline Compound & $\begin{array}{l}\text { HMLER } \\
\mathrm{IC}_{50}[\mu \mathrm{M}]\end{array}$ & $\begin{array}{l}\text { HMLER- } \\
\text { ShEcad } \\
\mathrm{IC}_{50}[\mu \mathrm{M}]\end{array}$ & $\begin{array}{c}\text { Mammosphere } \\
\mathrm{IC}_{50}[\mu \mathrm{M}]\end{array}$ \\
\hline 2 & $3.19 \pm 0.11$ & $3.40 \pm 0.05$ & $4.14 \pm 0.20$ \\
\hline 3 & $3.25 \pm 0.18$ & $3.43 \pm 0.10$ & $6.08 \pm 0.88$ \\
\hline 4 & $7.57 \pm 0.23$ & $12.70 \pm 0.14$ & $42.55 \pm 8.13$ \\
\hline 5 & $8.87 \pm 0.54$ & $12.90 \pm 0.14$ & $49.10 \pm 4.38$ \\
\hline salinomycin $^{1}$ & $11.40 \pm 0.40$ & $4.20 \pm 0.30$ & $18.50 \pm 1.50$ \\
\hline $\mathrm{L}^{2}$ & $12.91 \pm 0.71$ & $32.41 \pm 0.95$ & $64.29 \pm 0.20$ \\
\hline $\mathbf{L}^{3}$ & $11.20 \pm 0.10$ & $20.41 \pm 0.35$ & $52.06 \pm 0.31$ \\
\hline $\mathrm{CuCl}_{2} \cdot 2 \mathrm{H}_{2} \mathrm{O}^{1}$ & $47.55 \pm 0.18$ & $47.92 \pm 1.80$ & n.d. \\
\hline dichloro(1,10-phenanthroline)copper(II) ${ }^{1}$ & $4.90 \pm 0.17$ & $7.86 \pm 0.26$ & $9.49 \pm 0.20$ \\
\hline
\end{tabular}

${ }^{1}$ Taken from references $[10,13,27]$. n.d. not determined.

Breast CSCs are known to form three-dimensional, tumour-like structures, known as mammospheres when grown under low-attachment, serum-free conditions [28]. The ability of a given compound to inhibit mammosphere formation from single cell suspensions (with respect to number and size) is often used as a gauge for CSC potency. The ability of $\mathbf{2}-\mathbf{5}$ to inhibit HMLER-shEcad mammosphere formation was assessed using an inverted microscope. The addition of 2 and 3 (at $0.5 \mu \mathrm{M}$, a non-lethal dose after 5 days incubation) appreciably reduced the number of mammospheres formed, whereas equal dosage with 4 and 5 did not significantly decrease the number of mammospheres formed (Figure 2). Although 2 and 3 inhibited mammosphere formation to a significant level $(p<0.05)$, their inhibitory effect was lower than salinomycin (Figure 2). Specifically, 2 and 3 reduced the number of mammospheres formed by $32-35 \%$ compared to the untreated control, whereas salinomycin induced a $60 \%$ reduction in the number of mammospheres formed compared to the untreated control. All of the copper(II) complexes 2-5 decreased the size of mammospheres formed (upon treatment at the $\mathrm{IC}_{20}$ value for 5 days) to some extent, with 2 and 3 reducing the size more than 4 and 5 (Figure 3). Overall this shows that the presence of the 1,10-phenanthroline moiety in 2 and 3 enhances their mammosphere inhibitory effect. Salinomycin (upon treatment at the $\mathrm{IC}_{20}$ value for 5 days) markedly reduced mammosphere size (Figure S27). As expected, addition of the naphthol Schiff base ligands $\mathbf{L}^{2}$ and $\mathbf{L}^{3}$ (at $0.5 \mu \mathrm{M}$ or $\mathrm{IC}_{20}$ value, both non-lethal doses, after 5 days incubation) had little effect on the number and size of mammospheres formed (Figures 2 and S28). 


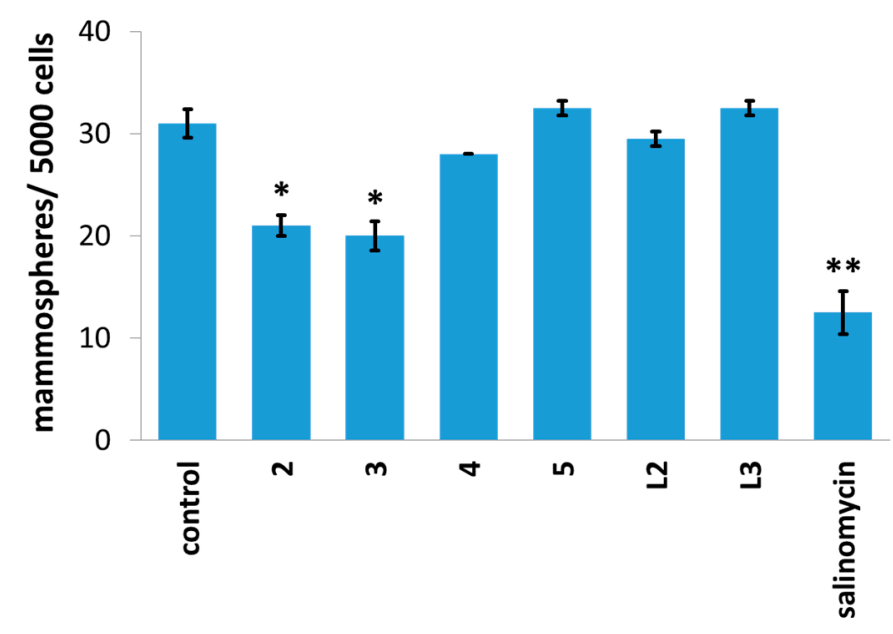

Figure 2. Representation of the number of mammospheres formed from HMLER-shEcad cell suspensions treated with $2-5, \mathbf{L}^{2}, \mathbf{L}^{3}$ or salinomycin at $0.5 \mu \mathrm{M}$, a non-lethal dose after 5 days incubation. Standard deviation was used to signify the associated errors. Student $t$-test, ${ }^{*}=p<0.05,{ }^{* *}=p<0.01$.
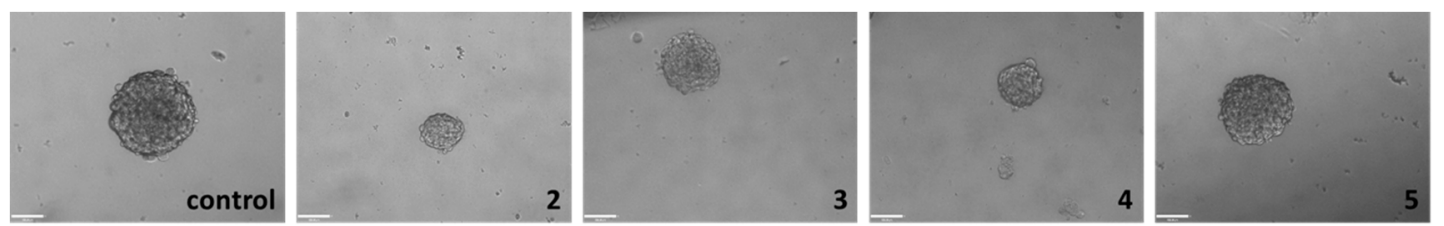

Figure 3. Bright-field images (taken using an inverted microscope) representative of untreated HMLER-shEcad mammospheres and those treated with $\mathbf{2}-\mathbf{5}$ for 5 days at their respective $\mathrm{IC}_{20}$ values. Scale bar $=100 \mu \mathrm{m}$.

To determine the ability of $\mathbf{2} \mathbf{- 5}$ to reduce mammosphere viability, TOX8 a resazurinbased reagent was used. The $\mathrm{IC}_{50}$ values (concentration required to reduce mammosphere viability by $50 \%$ ) were extrapolated from dose-response curves (Figures S29-S32) and are summarised in Table 1 . The $\mathrm{IC}_{50}$ values for $\mathbf{2}-\mathbf{5}$ were in the micromolar range, with the most effective complexes $\mathbf{2}$ and $\mathbf{3}$ displaying 4.5- and 3-fold greater mammosphere potency than salinomycin, respectively (Table 1) [13]. The mammosphere potency of $\mathbf{2}$ and $\mathbf{3}$ were significantly $(p<0.05)$ higher than 4 and 5 . This highlights the importance of the 1,10phenanthroline moiety in $\mathbf{2}$ and $\mathbf{3}$ to their mammosphere toxicity, and is consistent with the monolayer cytotoxicity results. Furthermore control studies showed that the potency of the naphthol Schiff base ligands $\mathbf{L}^{2}$ and $\mathbf{L}^{3}$, and dichloro(1,10-phenanthroline)copper(II) [11] towards HMLER-shEcad mammospheres was significantly lower $(p<0.05)$ than 2 and 3 (Figures S33 and S34, Table 1). Therefore, the mammosphere potency observed for $\mathbf{2}$ and $\mathbf{3}$ is likely to be due to the intact mammosphere uptake of the copper(II) complexes, which facilitates the concerted co-delivery of all the complex components.

\subsection{Mechanism of Action of the Copper(II) Complexes}

In order to better understand the discrepancy in breast CSC monolayer and mammosphere potency of the mono-cationic 1,10-phenanthroline-containing complexes 2 and 3 , and the corresponding neutral chloride-containing complexes 4 and 5, cellular uptake studies were performed. HMLER-shEcad cells were dosed with 2-5 (5 $\mu \mathrm{M}$ for $24 \mathrm{~h})$ and the copper content was determined by inductively coupled plasma mass spectrometry (ICP-MS). As depicted in Figure 4, the 1,10-phenanthroline-containing complexes 2 (124 ng of $\mathrm{Cu} / 10^{6}$ cells) and 3 (188 ng of $\mathrm{Cu} / 10^{6}$ cells) were internalized by HMLER-shEcad cells to a significantly $(p<0.05)$ greater extent than the corresponding neutral chloride-containing complexes 4 ( $78 \mathrm{ng}$ of $\mathrm{Cu} / 10^{6}$ cells) and 5 (95 ng of $\mathrm{Cu} / 10^{6}$ cells). The higher breast CSC 
uptake of $\mathbf{2}$ relative to $\mathbf{4}$, and 3 relative to 5 could explain the variance in breast CSC potency of the complexes (with and without 1,10-phenanthroline).

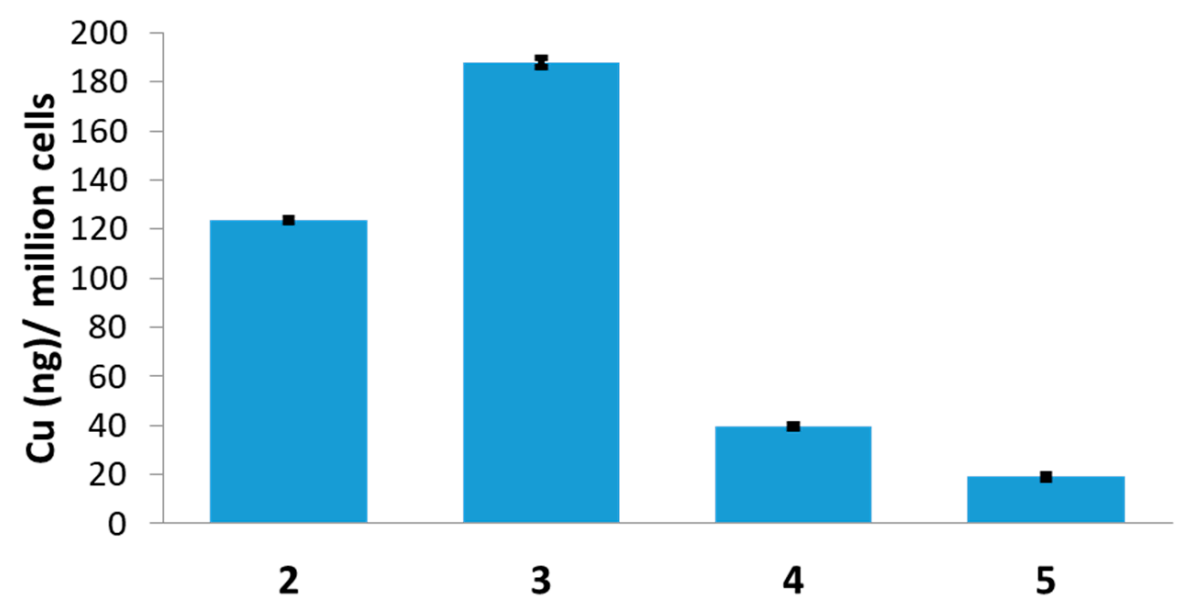

Figure 4. Copper content (ng of $\mathrm{Cu} / 10^{6}$ cells) in HMLER-shEcad cells treated with $\mathbf{2 - 5}$ (5 $\mu \mathrm{M}$ for $24 \mathrm{~h}$ ).

Copper(II) complexes bearing Schiff base and/or phenanthroline ligands are known to induce cell death by elevating intracellular ROS levels [10-13]. To determine if 2- and 3-induced breast CSC toxicity is related to ROS production, intracellular ROS levels were quantified at different exposure times $(0.5-24 \mathrm{~h})$ using 6-carboxy- $2^{\prime}, 7^{\prime}$-dichlorodihydrofluorescein diacetate (DCFH-DA), a well-established ROS indicator. HMLER-shEcad cells treated with $2\left(2 \times \mathrm{IC}_{50}\right.$ value) displayed a significant increase in ROS levels after $1 \mathrm{~h}$ exposure $(92.5 \%$ increase, $p<0.05)$ relative to untreated control cells (Figure S35). Shorter $(0.5 \mathrm{~h})$ or prolonged (3-24 h) exposure of $\mathbf{2}$ did not increase intracellular ROS levels compared to untreated cells. HMLER-shEcad cells dosed with $3\left(2 \times \mathrm{IC}_{50}\right.$ value) displayed a significant increase in ROS levels after $0.5 \mathrm{~h}$ exposure $(75.1 \%$ increase, $p<0.05)$ relative to untreated control cells (Figure S36). Prolonged (1-24 h) exposure of 3 did not increase intracellular ROS levels compared to untreated cells, although a statistically insignificant increase $(p>0.05)$ in ROS levels was observed after $3 \mathrm{~h}$ exposure. Therefore, for HMLER-shEcad cells treated with $\mathbf{2}$ and $\mathbf{3}$, a sharp ROS burst occurs within the first hour of exposure and then ROS levels attenuate to levels observed in untreated control cells. Similar time-dependent ROS generation properties have been previously reported for other CSC-potent copper(II) complexes [12,13]. $\mathrm{H}_{2} \mathrm{O}_{2}$-treated (positive control, $150 \mu \mathrm{M}$ for 0.5-24 h) HMLER-shEcad cells exhibited a significant increase $(p<0.05)$ in ROS levels after short (0.5-3 h, up to 14-fold) and long (6-24 h, up to 2-fold) exposure times, compared to untreated control cells (Figure S37). Collectively, the ROS studies suggest that 2- and 3-induced breast CSC death could be associated to intracellular ROS generation.

\section{Materials and Methods}

\subsection{General Procedures}

All synthetic procedures were performed under normal atmospheric conditions. Fourier transform infrared (FTIR) spectra were recorded with an IRAffinity-1S Shimadzu spectrophotometer. Electron spray ionisation mass spectra were recorded on a Micromass Quattro spectrometer. UV-Vis absorption spectra were recorded on a Cary $3500 \mathrm{UV}$-Vis spectrophotometer. ${ }^{1} \mathrm{H}$ and ${ }^{13} \mathrm{C}$ NMR spectra were recorded on a BrukerAvance $400 \mathrm{MHz}$ Ultrashield NMR spectrometer. ${ }^{1} \mathrm{H}$ NMR spectra were referenced internally to residual solvent peaks, and chemical shifts are expressed relative to tetramethylsilane, $\operatorname{SiMe}_{4}(\delta=0 \mathrm{ppm})$. Elemental analysis of the compounds prepared was performed commercially by London Metropolitan University or the University of Cambridge. 2-hydroxy-1-naphthaldehyde, 2-(methylthio)ethylamine, 2-(ethylthio)ethylamine, 1,10-phenanthroline, $\mathrm{Cu}\left(\mathrm{NO}_{3}\right)_{2} \cdot 3 \mathrm{H}_{2} \mathrm{O}$, 
$\mathrm{CuCl}_{2} \cdot 2 \mathrm{H}_{2} \mathrm{O}$, and $\mathrm{NaPF}_{6}$ were purchased from Sigma Aldrich or Alfa Aesar and used as received.

\subsection{Synthesis of (E)-1-(((2-(Methylthio)ethyl)imino)methyl)naphthalen-2-ol, $\mathbf{L}^{\mathbf{2}}$}

A mixture of 2-hydroxy-1-naphthaldehyde (344 mg, $2.0 \mathrm{mmol})$ and 2-(methylthio) ethylamine $(191 \mathrm{mg}, 2.1 \mathrm{mmol})$ were refluxed in ethanol $(20 \mathrm{~mL})$ for $16 \mathrm{~h}$. The reaction mixture was then evaporated under vacuum to afford $\mathbf{L}^{2}$ as an orange solid (472 $\left.\mathrm{mg}, 96 \%\right)$; ${ }^{1} \mathrm{H}$ NMR (400 MHz, DMSO-d $): \delta 13.93$ (s, 1H, OH), $9.11(\mathrm{~d}, 1 \mathrm{H}, \mathrm{N}=\mathrm{CH}), 8.06(\mathrm{~d}, 1 \mathrm{H}$, Ar-H), 7.73 (d, 1H, Ar-H), $7.64(\mathrm{~d}, 1 \mathrm{H}, \mathrm{Ar}-H), 7.43$ (ddd, 1H, Ar-H), 7.19 (ddd, 1H, Ar-H), $6.71(\mathrm{~d}, 1 \mathrm{H}, \mathrm{Ar}-\mathrm{H}), 3.84\left(\mathrm{dd}, 2 \mathrm{H}, \mathrm{CH}_{2}\right), 2.83\left(\mathrm{t}, 2 \mathrm{H}, \mathrm{CH}_{2}\right), 2.13\left(\mathrm{~s}, 3 \mathrm{H}, \mathrm{CH}_{3}\right) ;{ }^{13} \mathrm{C}$ NMR $(162$ MHz, DMSO-d 6$): \delta 177.85(\mathrm{~N}=\mathrm{CH}), 159.74(A r), 137.60(A r), 134.85(A r), 129.34(A r), 128.34$ (Ar), $126.05(A r), 125.66(A r), 122.62(A r), 118.95(A r), 106.13(A r), 50.33\left(C_{2}\right), 34.47\left(\mathrm{CH}_{2}\right)$, $15.05\left(\mathrm{CH}_{3}\right)$; IR (solid, ATR, $\left.\mathrm{cm}^{-1}\right)$ : 3021, 2971, 2917, 1616, 1541, 1529, 1491, 1439, 1399, 1354, 1314, 1282, 1254, 1193, 1177, 1137, 1040, 996, 955, 924, 879, 855, 827, 743, 723, 686, 654, 541, 513, 497, 481, 437, 413; HR ESI-MS Calcd. for $\mathrm{C}_{14} \mathrm{H}_{16} \mathrm{NOS}[\mathrm{M}+\mathrm{H}]^{+} 246.0953$ a.m.u. Found $[\mathrm{M}+\mathrm{H}]^{+}$: 246.0954 a.m.u.; Anal. Calcd. for $\mathrm{C}_{14} \mathrm{H}_{15} \mathrm{NOS} \cdot 0.25 \mathrm{H}_{2} \mathrm{O}(\%): \mathrm{C}, 67.30 ; \mathrm{H}, 6.25 ; \mathrm{N}$, 5.61. Found: C, 67.62; H, 6.06; N, 5.99 .

\subsection{Synthesis of (E)-1-(((2-(Ethylthio)ethyl)imino)methyl)naphthalen-2-ol, $\mathbf{L}^{3}$}

A mixture of 2-hydroxy-1-naphthaldehyde (172 mg, $1.0 \mathrm{mmol})$ and 2-(ethylthio) ethylamine $(116 \mathrm{mg}, 1.1 \mathrm{mmol})$ were refluxed in ethanol $(20 \mathrm{~mL})$ for $16 \mathrm{~h}$. The reaction mixture was evaporated under vacuum to afford $\mathbf{L}^{3}$ as an orange solid $(259 \mathrm{mg}, 100 \%) ;{ }^{1} \mathrm{H}$ NMR (400 MHz, DMSO-d $)$ : $\delta 13.94(\mathrm{~s}, 1 \mathrm{H}, \mathrm{OH}), 9.10(\mathrm{~d}, 1 \mathrm{H}, \mathrm{N}=\mathrm{CH}), 8.06(\mathrm{~d}, 1 \mathrm{H}, \mathrm{Ar}-H)$, $7.73(\mathrm{~d}, 1 \mathrm{H}, \mathrm{Ar}-\mathrm{H}), 7.63(\mathrm{dd}, 1 \mathrm{H}, \mathrm{Ar}-\mathrm{H}), 7.43$ (ddd, 1H, Ar-H), 7.19 (ddd, 1H, Ar-H), 6.72 $(\mathrm{d}, 1 \mathrm{H}, \mathrm{Ar}-\mathrm{H}), 3.82\left(\mathrm{dd}, 2 \mathrm{H}, \mathrm{CH}_{2}\right), 2.86\left(\mathrm{t}, 2 \mathrm{H}, \mathrm{CH}_{2}\right), 2.60\left(\mathrm{q}, 2 \mathrm{H}, \mathrm{CH}_{2}\right), 1.20\left(\mathrm{t}, 3 \mathrm{H}, \mathrm{CH}_{3}\right)$; ${ }^{13} \mathrm{C}$ NMR (162 MHz, DMSO-d $): \delta 177.84(\mathrm{~N}=\mathrm{CH}), 159.70(A r), 137.60(A r), 134.85(A r)$, $129.34(A r), 128.34(A r), 126.04(A r), 125.66(A r), 122.61(A r), 118.95(A r), 106.12(A r), 50.97$ $\left(\mathrm{CH}_{2}\right), 31.96\left(\mathrm{CH}_{2}\right), 25.33\left(\mathrm{CH}_{2}\right), 15.28\left(\mathrm{CH}_{3}\right)$; IR (solid, ATR, $\left.\mathrm{cm}^{-1}\right): 3049,3025,2969,2920$, 1610, 1540, 1493, 1440, 1402, 1344, 1256, 1206, 1183, 1137, 1070, 1034, 995, 961, 867, 832, 740, 638, 542, 515, 504, 480, 434, 414; HR ESI-MS Calcd. for $\mathrm{C}_{15} \mathrm{H}_{18} \mathrm{NOS}[\mathrm{M}+\mathrm{H}]^{+} 260.1109$ a.m.u. Found $[\mathrm{M}+\mathrm{H}]^{+}: 260.1112$ a.m.u.; Anal. Calcd. for $\mathrm{C}_{15} \mathrm{H}_{17} \mathrm{NOS} \cdot 0.2 \mathrm{H}_{2} \mathrm{O}(\%): \mathrm{C}, 68.51$; $\mathrm{H}, 6.67 ; \mathrm{N}, 5.33$. Found: C, 68.62; H, 6.38; N, 5.55.

\subsection{Synthesis of $\left[\mathrm{Cu}\left(\mathbf{L}^{2}\right) 1,10\right.$-Phenanthroline $]\left[P F_{6}\right], \mathbf{2}$}

1,10-phenanthroline $(74 \mathrm{mg}, 0.41 \mathrm{mmol})$ and $\mathrm{Cu}\left(\mathrm{NO}_{3}\right)_{2} \cdot 3 \mathrm{H}_{2} \mathrm{O}(99 \mathrm{mg}, 0.41 \mathrm{mmol})$ dissolved in methanol $(10 \mathrm{~mL})$ were stirred at room temperature for $0.5 \mathrm{~h}$. The colour of the solution changed from blue to light green. $\mathbf{L}^{2}(100 \mathrm{mg}, 0.41 \mathrm{mmol})$ in methanol $(10 \mathrm{~mL})$ was added dropwise. The dark green mixture was stirred at room temperature for $72 \mathrm{~h}$. The mixture was then filtered to remove the precipitate. The filtrate was reduced to $\sim 10 \mathrm{~mL}$. An excess of $\mathrm{NaPF}_{6}(250 \mathrm{mg}, 1.5 \mathrm{mmol})$ in water $(50 \mathrm{~mL})$ was added and the mixture stirred for $0.5 \mathrm{~h}$. The resultant precipitate was collected and washed thoroughly with water and diethyl ether to give 2 as a dark green solid (116 mg, 45\%); IR (solid, ATR, $\mathrm{cm}^{-1}$ ): 1618, 1602, $1585,1540,1518,1430,1413,1392,1366,1342,1254,1223,1194,1144,1106,1029,979,828$, 752, 722, 647, 557, 523, 476, 416; HR ESI-MS Calcd. for $\mathrm{C}_{26} \mathrm{H}_{22} \mathrm{CuN}_{3} \mathrm{OS}\left[\mathrm{M}-\mathrm{PF}_{6}\right]^{+} 487.0780$ a.m.u. Found $\left[\mathrm{M}-\mathrm{PF}_{6}\right]^{+} 487.0775$ a.m.u.; Anal. Calcd. for $\mathrm{C}_{26} \mathrm{H}_{22} \mathrm{CuN}_{3} \mathrm{OSPF}_{6}(\%): \mathrm{C}, 49.33$; H, 3.50; N, 6.64. Found: C, 49.14; H, 3.34; N, 6.46.

\subsection{Synthesis of $\left[\mathrm{Cu}\left(\mathbf{L}^{3}\right) 1,10-P h e n a n t h r o l i n e\right]\left[P F_{6}\right], 3$}

1,10-phenanthroline $(110 \mathrm{mg}, 0.61 \mathrm{mmol})$ and $\mathrm{Cu}\left(\mathrm{NO}_{3}\right)_{2} \cdot 3 \mathrm{H}_{2} \mathrm{O}(147 \mathrm{mg}, 0.61 \mathrm{mmol})$ dissolved in methanol $(10 \mathrm{~mL})$ were stirred at room temperature for $0.5 \mathrm{~h}$. The colour of the solution changed from blue to light green. $\mathrm{L}^{3}(160 \mathrm{mg}, 0.62 \mathrm{mmol})$ in methanol $(10 \mathrm{~mL})$ was added dropwise. The dark green mixture was stirred at room temperature for $72 \mathrm{~h}$. The mixture was then filtered to remove the precipitate. The filtrate was reduced to $10 \mathrm{~mL}$. An excess of $\mathrm{NaPF}_{6}(400 \mathrm{mg}, 2.4 \mathrm{mmol})$ in water $(\sim 30 \mathrm{~mL})$ was added and the mixture stirred 
for $0.5 \mathrm{~h}$. The resultant precipitate was collected and washed thoroughly with water and diethyl ether to give 3 as a green solid (272 mg, 69\%); IR (solid, ATR, $\mathrm{cm}^{-1}$ ): 1616, 1604, 1583, 1539, 1509, 1460, 1437, 1428, 1416, 1393, 1363, 1345, 1254, 1224, 1187, 1145, 1104, 1094, 1036, 1006, 979, 828, 751, 725, 645, 555, 521, 490, 476, 450, 421, 387; HR ESI-MS Calcd. for $\mathrm{C}_{27} \mathrm{H}_{24} \mathrm{CuN}_{3} \mathrm{OS}\left[\mathrm{M}-\mathrm{PF}_{6}\right]^{+} 501.0936$ a.m.u. Found [M-PF 6$]^{+} 501.0936$ a.m.u.; Anal. Calcd. for $\mathrm{C}_{27} \mathrm{H}_{24} \mathrm{CuN}_{3} \mathrm{OSPF}_{6}$ (\%): C, 50.12; H, 3.74; N, 6.49. Found: C, 49.79; H, 3.45; N, 6.18.

\subsection{Synthesis of $\left[\mathrm{Cu}\left(\mathbf{L}^{2}\right) \mathrm{Cl}\right], \mathbf{4}$}

$\mathrm{L}^{2}(96.4 \mathrm{mg}, 0.39 \mathrm{mmol})$ in methanol $(20 \mathrm{~mL})$ was added to $\mathrm{CuCl}_{2} \cdot 2 \mathrm{H}_{2} \mathrm{O}(66.5 \mathrm{mg}$, $0.39 \mathrm{mmol})$ in methanol $(5 \mathrm{~mL})$. The dark green mixture was stirred overnight. The resultant precipitate was collected and washed with cold methanol and diethyl ether to yield 4 as a dark green solid $(20 \mathrm{mg})$. The filtrate was reduced and left overnight in the freezer $\left(-20^{\circ} \mathrm{C}\right)$ to yield a second crop of 4 as a dark green solid (16 mg) (total $36 \mathrm{mg}, 27 \%$ ); IR (solid, ATR, cm ${ }^{-1}$ ): 1615, 1604, 1589, 1537, 1503, 1452, 1431, 1409, 1392, 1359, 1339, 1306, 1250, 1210, 1183, 1164, 1140, 1089, 1029, 976, 957, 940, 859, 825, 778, 765, 746, 646, 583, 553, 516, 474, 448, 417, 387; HR ESI-MS Calcd. for $\mathrm{C}_{14} \mathrm{H}_{14} \mathrm{CuNOS}[\mathrm{M}-\mathrm{Cl}]^{+} 307.0092$ a.m.u. Found [M-Cl] 307.0096 a.m.u.; Anal. Calcd. for $\mathrm{C}_{14} \mathrm{H}_{14} \mathrm{CuNOSCl}$ (\%): C, 48.98; H, 4.11; N, 4.08. Found: C, 48.77; H, 3.98; $\mathrm{N}, 4.02$.

\subsection{Synthesis of $\left[\mathrm{Cu}\left(\mathbf{L}^{3}\right) \mathrm{Cl}\right], \mathbf{5}$}

$\mathbf{L}^{3}(119 \mathrm{mg}, 0.46 \mathrm{mmol})$ in methanol $(5 \mathrm{~mL})$ was added to $\mathrm{CuCl}_{2} \cdot 2 \mathrm{H}_{2} \mathrm{O}(78 \mathrm{mg}$, $0.46 \mathrm{mmol})$ in methanol $(5 \mathrm{~mL})$. The dark green mixture was refluxed for $2 \mathrm{~h}$. The mixture was then put in the freezer $\left(-20^{\circ} \mathrm{C}\right)$ overnight. The resultant precipitate was collected and washed with cold methanol and diethyl ether to yield 5 as a dark green solid (52 mg, 32\%); IR (solid, ATR, cm ${ }^{-1}$ ): 1614, 1604, 1537, 1507, 1454, 1433, 1412, 1391, 1361, 1340, 1308, 1253, 1206, 1183, 1172, 1162, 1141, 1093, 1077, 1033, 1000, 977, 949, 869, 830, 752, 644, 584, 558, 549, 513, 473, 449, 421, 384; HR ESI-MS Calcd. for $\mathrm{C}_{15} \mathrm{H}_{16} \mathrm{CuNOS}$ [M-Cl] ${ }^{+} 321.0249$ a.m.u. Found [M-Cl] ${ }^{+} 321.0257$ a.m.u.; Anal. Calcd. for $\mathrm{C}_{15} \mathrm{H}_{16} \mathrm{CuNOSCl}(\%)$ : C, 50.42; H, 4.51; N, 3.92. Found: C, 50.75; H, 4.25; N, 3.83.

\subsection{X-ray Single Crystal Diffraction Analysis}

Single crystals of complexes 2 and 3 were obtained by slow evaporation of an acetone solution of $\mathbf{2}$ and by vapour diffusion of diethyl ether into an acetonitrile solution of 3 . Crystals suitable for X-ray diffraction analysis were selected and mounted on a Bruker Apex 2000 CCD area detector diffractometer using standard procedures. Data was collected using graphite-monochromated Mo-K $\alpha$ radiation $(\lambda=0.71073)$ at $150(2) \mathrm{K}$. Absorption corrections were applied using a multiscan method (SADABS) [29]. The structures were solved using SHELXS [30]; the datasets were refined by full-matrix least-squares on all unique $F^{2}$ values, with anisotropic displacement parameters for all non-hydrogen atoms, and with constrained riding hydrogen geometries [31]; $U_{\text {iso }}(\mathrm{H})$ was set at 1.2 (1.5 for methyl groups) times $U_{\text {eq }}$ of the parent atom. The largest features in final difference syntheses were close to heavy atoms and were of no chemical significance. SHELX was employed through OLEX2 for structure solution and refinement [29,30,32]. ORTEP-3 and POV-Ray were employed for molecular graphics [33]. The structures have been deposited with the Cambridge Crystallographic Data Centre (CCDC 2046679 and 2046680). This information can be obtained free of charge from www.ccdc.cam.ac.uk/data_request/cif.

\subsection{Measurement of Water-Octanol Partition Coefficient $(\log P)$}

The LogP values for $\mathbf{2}-\mathbf{5}$ were determined using the shake-flask method and UV-Vis spectroscopy. The 1-octanol used in this experiment was pre-saturated with water. An aqueous solution of $\mathbf{2 - 5}(500 \mu \mathrm{L}, 100 \mu \mathrm{M})$ was incubated with 1-octanol (500 $\mu \mathrm{L})$ in a $1.5 \mathrm{~mL}$ tube. The tube was shaken at room temperature for $24 \mathrm{~h}$. The two phases were separated by centrifugation and the 2-5 content in each phase was determined by UV-Vis spectroscopy. 


\subsection{Cell Lines and Cell Culture Conditions}

R. A. Weinberg (Whitehead Institute, MIT) (Cambridge, USA) generously gave the human mammary epithelial cell lines, HMLER and HMLER-shEcad, used in this study. The cells were grown in Mammary Epithelial Cell Growth Medium (MEGM) with supplements and growth factors (BPE, hydrocortisone, hEGF, insulin, and gentamicin/amphotericin-B). Standard cell culture conditions were used to grow the cells $\left(310 \mathrm{~K}, 5 \% \mathrm{CO}_{2}\right)$.

\subsection{Cytotoxicity MTT Assay}

The cytotoxicity of $\mathbf{2}-\mathbf{5}, \mathbf{L}^{2}$, and $\mathbf{L}^{3}$ was determined using the colorimetric MTT assay. Five thousand HMLER and HMLER-shEcad cells were added to each well of a 96-well plate. Upon allowing the cells to attach to the bottom of each well of a 96-well plate overnight, different concentrations of the test compounds $(0.2-100 \mu \mathrm{M})$ were added, and incubated for $72 \mathrm{~h}$ (total volume $200 \mu \mathrm{L}$ ). $10 \mathrm{mM}$ stock solutions of the compounds in DMSO were prepared and appropriately diluted using Mammary Epithelial Cell Growth Medium (MEGM). The untreated control wells contained 0.5\% DMSO, which was the final concentration of DMSO in each treated well. Upon $72 \mathrm{~h}$ incubation, a $4 \mathrm{mg} \mathrm{mL}^{-1}$ solution of MTT dissolved in PBS was added to each well $(20 \mu \mathrm{L})$. The 96-well plate was then incubated for an additional $4 \mathrm{~h}$. After aspiration of the MEGM/MTT solution in each well, $200 \mu \mathrm{L}$ of DMSO was added to each well to dissolve any purple formazan crystals. The absorbance of the resultant solutions in each well was read at $550 \mathrm{~nm}$. The absorbance values corresponding to each well were normalised to DMSO-containing control wells and plotted as concentration of test compound versus \% cell viability. $\mathrm{IC}_{50}$ values were calculated from the resulting dose dependent curves. The reported $\mathrm{IC}_{50}$ values are the average of three independent experiments $(n=18)$.

\subsection{Tumorsphere Formation and Viability Assay}

Five thousand HMLER-shEcad cells were added to each well of an ultralow-attachment 96-well plate (Corning) in MEGM containing B27 (Invitrogen), $20 \mathrm{ng} / \mathrm{mL}$ EGF, and $4 \mu \mathrm{g} / \mathrm{mL}$ heparin (Sigma), and incubated for $120 \mathrm{~h}$. The HMLER-shEcad cells were also treated with 2-5, $\mathbf{L}^{2}, \mathrm{~L}^{3}$, and salinomycin $(0-133 \mu \mathrm{M})$. Wells where HMLER-shEcad mammospheres were incubated with $2-5, \mathbf{L}^{2}, \mathbf{L}^{3}$, and salinomycin (at $0.5 \mu \mathrm{M}$ and their respective $\mathrm{IC}_{20}$ values for 5 days) were manually counted and imaged using an inverted microscope. The resazurin-based dye, TOX8 (Sigma) was used to determine mammosphere viability. Upon incubation for $16 \mathrm{~h}$, the fluorescence of the solutions in each well was read at 590 $\mathrm{nm}\left(\lambda_{\mathrm{ex}}=560 \mathrm{~nm}\right)$. The fluorescence values corresponding to each well were normalised to DMSO-containing controls and plotted as concentration of test compound versus \% mammospheres viability. $\mathrm{IC}_{50}$ values were calculated from the resulting dose dependent curves. The reported $\mathrm{IC}_{50}$ values are the average of two independent experiments, each consisting of two replicates per concentration level.

\subsection{Cellular Uptake}

To determine the internalisation of $\mathbf{2}-\mathbf{5}$ by HMLER-shEcad cells, about one million HMLER-shEcad cells were seeded in separate $60 \mathrm{~mm}$ Petri dishes overnight. The HMLERshEcad cells were then dosed with 2-5 (at $5 \mu \mathrm{M}$ ) and incubated for $24 \mathrm{~h}$. After the incubation period, the cells were harvested using standard procedures and the number of cells was counted using a haemocytometer. The resultant cellular pellets were dissolved in $65 \%$ $\mathrm{HNO}_{3}(250 \mu \mathrm{L})$ overnight. The solutions were then appropriately diluted using UltraPure water and analysed using inductively coupled plasma mass spectrometry (ICP-MS, ThermoScientific ICAP-Qc quadrupole ICP mass spectrometer). The copper levels found in the cellular pellets are given as $\mathrm{Cu}$ (ng) per million cells. The data presented corresponds to the mean of four determinations for each data point. 


\subsection{Intracellular ROS Assay}

HMLER-shEcad cells $\left(5 \times 10^{3}\right)$ were seeded in each well of a 96-well plate. After incubating the cells overnight, they were treated with 2 and $3\left(2 \times \mathrm{IC}_{50}\right.$ value for $\left.0.5-24 \mathrm{~h}\right)$ and incubated with 6-carboxy-2 $2^{\prime}, 7^{\prime}$-dichlorodihydrofluorescein diacetate $(20 \mu \mathrm{M})$ for $90 \mathrm{~min}$. The intracellular ROS level was determined by measuring the fluorescence of the solutions in each well at $529 \mathrm{~nm}\left(\lambda_{\mathrm{ex}}=504 \mathrm{~nm}\right)$.

\section{Conclusions}

In summary, we report the preparation, spectroscopic and analytical characterisation, and in vitro anti-breast CSC properties of two copper(II) complexes (2 and 3 ) bearing a naphthol Schiff base ligand $\left(\mathbf{L}^{2}\right.$ or $\left.\mathbf{L}^{3}\right)$ and 1,10-phenanthroline. According to the $\mathbf{X}$-ray crystal structures, the cationic components of $\mathbf{2}$ and $\mathbf{3}$ exhibit five-coordinate distorted trigonal bipyramid geometries. Notably, 2 and 3 simultaneously kill bulk breast cancer and breast CSCs in the micromolar range. As 2 and 3 are equipotent towards bulk breast cancer cells and breast CSCs, they have the potential to remove heterogenous breast tumour populations (containing bulk breast cancer cells and breast CSCs) with a single (micromolar) dose. The 1,10-phenanthroline moiety is a contributing factor in the breast CSC potency of 2 and 3, and this is shown by the fact that the corresponding chloridecontaining complexes without 1,10-phenanthroline 4 and 5 are 3.7-3.8-fold (monolayer) and 8.6-15.5-fold (mammosphere) less toxic towards breast CSCs than 2 and 3. Remarkably, 2 and 3 reduced breast CSC mammosphere viability to a greater extent (up to 4.5 -fold lower $\mathrm{IC}_{50}$ value) than salinomycin, an established anti-breast CSC agent. Cellular uptake studies show that $\mathbf{2}$ and $\mathbf{3}$ were internalised by breast CSCs more readily than the corresponding chloride-containing complexes 4 and 5, which could explain their differences in breast CSC potency. Furthermore, $\mathbf{2}$ and $\mathbf{3}$ are able to generate significant levels of intracellular ROS (75-93\% increase relative to untreated control breast CSCs) after short exposure times $(0.5-1 \mathrm{~h})$, and this may be the mechanism by which they induce breast CSC death. Overall our studies highlight the promising anti-CSC properties of redox-modulating copper(II) complexes containing Schiff base and 1,10-phenanthroline ligands. These findings support the continued development of this class of redox-active metal complexes as potential CSC-directed chemotherapeutics. Future studies will focus on understanding the full cytotoxic and immunological mechanism of action of this family of copper(II) complexes and determining their translatable scope.

Supplementary Materials: The following are available online at https:/ / www.mdpi.com/2304-6740/ 9/1/5/s1, Figures S1-S37, Tables S1-S4, and the CIF and corresponding checkCIF output files.

Author Contributions: K.S. (Kogularamanan Suntharalingam) and J.N.-S. conceived and designed the experiments; J.N.-S., A.J., K.S. (Kuldip Singh), F.O. and K.S. (Kogularamanan Suntharalingam) performed the experiments; J.N.-S., A.J., K.S. (Kuldip Singh), F.O. and K.S. (Kogularamanan Suntharalingam) analyzed the data; K.S. (Kogularamanan Suntharalingam), and J.N.-S. wrote the manuscript; J.N.-S., A.J., K.S. (Kuldip Singh), F.O. and K.S. (Kogularamanan Suntharalingam) reviewed and edited the manuscript. All authors have read and agreed to the published version of the manuscript.

Funding: K.S. is supported by an EPSRC New Investigator Award (EP/S005544/1).

Institutional Review Board Statement: Not applicable.

Informed Consent Statement: Not applicable.

Data Availability Statement: Not applicable.

Acknowledgments: We are grateful to Robert Weinberg for providing the HMLER and HMLERshEcad cell lines used in this study.

Conflicts of Interest: The authors declare no conflict of interest. 


\section{References}

1. Still 1 in 4 Deaths Caused by Cancer in the EU. Available online: https://ec.europa.eu/eurostat/documents/2995521/7149996/ 3-03022016-BP-EN.pdf/0bbc3389-8c0d-44a0-9b0c-2a0bff49f466 (accessed on 3 February 2016).

2. Luengo-Fernandez, R.; Leal, J.; Gray, A.; Sullivan, R. Economic burden of cancer across the European Union: A population-based cost analysis. Lancet Oncol. 2013, 14, 1165-1174. [CrossRef]

3. Al-Hajj, M.; Wicha, M.S.; Benito-Hernandez, A.; Morrison, S.J.; Clarke, M.F. Prospective identification of tumorigenic breast cancer cells. Proc. Natl. Acad. Sci. USA 2003, 100, 3983-3988. [CrossRef] [PubMed]

4. Gupta, P.B.; Chaffer, C.L.; Weinberg, R.A. Cancer stem cells: Mirage or reality? Nat. Med. 2009, 15, 1010-1012. [CrossRef] [PubMed]

5. $\quad$ Balic, M.; Lin, H.; Young, L.; Hawes, D.; Giuliano, A.; McNamara, G.; Datar, R.H.; Cote, R.J. Most early disseminated cancer cells detected in bone marrow of breast cancer patients have a putative breast cancer stem cell phenotype. Clin. Cancer Res. 2006, 12, 5615-5621. [CrossRef] [PubMed]

6. Owens, T.W.; Naylor, M.J. Breast cancer stem cells. Front. Physiol. 2013, 4, 225. [CrossRef] [PubMed]

7. Calcagno, A.M.; Salcido, C.D.; Gillet, J.P.; Wu, C.P.; Fostel, J.M.; Mumau, M.D.; Gottesman, M.M.; Varticovski, L.; Ambudkar, S.V. Prolonged drug selection of breast cancer cells and enrichment of cancer stem cell characteristics. J. Natl. Cancer Inst. 2010, 102, 1637-1652. [CrossRef] [PubMed]

8. Phillips, T.M.; McBride, W.H.; Pajonk, F. The response of CD24-/low $/$ CD44 $4^{+}$breast cancer-initiating cells to radiation. J. Natl. Cancer Inst. 2006, 98, 1777-1785. [CrossRef]

9. Laws, K.; Suntharalingam, K. The Next Generation of Anticancer Metallopharmaceuticals: Cancer Stem Cell-Active Inorganics. ChemBioChem 2018, 19, 2246-2253. [CrossRef]

10. Boodram, J.N.; McGregor, I.J.; Bruno, P.M.; Cressey, P.B.; Hemann, M.T.; Suntharalingam, K. Breast Cancer Stem Cell Potent Copper(II)-Non-Steroidal Anti-Inflammatory Drug Complexes. Angew. Chem. Int. Ed. 2016, 55, 2845-2850. [CrossRef]

11. Eskandari, A.; Boodram, J.N.; Cressey, P.B.; Lu, C.; Bruno, P.M.; Hemann, M.T.; Suntharalingam, K. The breast cancer stem cell potency of copper(II) complexes bearing nonsteroidal anti-inflammatory drugs and their encapsulation using polymeric nanoparticles. Dalton Trans. 2016, 45, 17867-17873. [CrossRef]

12. Lu, C.; Eskandari, A.; Cressey, P.B.; Suntharalingam, K. Cancer Stem Cell and Bulk Cancer Cell Active Copper(II) Complexes with Vanillin Schiff Base Derivatives and Naproxen. Chem. Eur. J. 2017, 23, 11366-11374. [CrossRef] [PubMed]

13. Lu, C.; Laws, K.; Eskandari, A.; Suntharalingam, K. A reactive oxygen species-generating, cyclooxygenase-2 inhibiting, cancer stem cell-potent tetranuclear copper(II) cluster. Dalton Trans. 2017, 46, 12785-12789. [CrossRef] [PubMed]

14. Marzano, C.; Pellei, M.; Tisato, F.; Santini, C. Copper complexes as anticancer agents. Anticancer Agents Med. Chem. 2009, 9, 185-211. [CrossRef] [PubMed]

15. Santini, C.; Pellei, M.; Gandin, V.; Porchia, M.; Tisato, F.; Marzano, C. Advances in Copper Complexes as Anticancer Agents. Chem. Rev. 2014, 114, 815-862. [CrossRef]

16. Galindo-Murillo, R.; Garcia-Ramos, J.C.; Ruiz-Azuara, L.; Cheatham, T.E., 3rd; Cortes-Guzman, F. Intercalation processes of copper complexes in DNA. Nucleic Acids Res. 2015, 43, 5364-5376. [CrossRef]

17. Ruiz-Azuara, L.; Bravo-Gomez, M.E. Copper compounds in cancer chemotherapy. Curr. Med. Chem. 2010, 17, 3606-3615. [CrossRef]

18. Vertiz, G.; Garcia-Ortuno, L.E.; Bernal, J.P.; Bravo-Gomez, M.E.; Lounejeva, E.; Huerta, A.; Ruiz-Azuara, L. Pharmacokinetics and hematotoxicity of a novel copper-based anticancer agent: Casiopeina III-Ea, after a single intravenous dose in rats. Fundam. Clin. Pharmacol. 2014, 28, 78-87. [CrossRef]

19. Wehbe, M.; Leung, A.W.Y.; Abrams, M.J.; Orvig, C.; Bally, M.B. A Perspective-Can copper complexes be developed as a novel class of therapeutics? Dalton Trans. 2017, 46, 10758-10773. [CrossRef]

20. Silva-Platas, C.; Villegas, C.A.; Oropeza-Almazan, Y.; Carranca, M.; Torres-Quintanilla, A.; Lozano, O.; Valero-Elizondo, J.; Castillo, E.C.; Bernal-Ramirez, J.; Fernandez-Sada, E.; et al. Ex Vivo Cardiotoxicity of Antineoplastic Casiopeinas Is Mediated through Energetic Dysfunction and Triggered Mitochondrial-Dependent Apoptosis. Oxid. Med. Cell Longev. 2018, $2018,8949450$. [CrossRef]

21. Diehn, M.; Cho, R.W.; Lobo, N.A.; Kalisky, T.; Dorie, M.J.; Kulp, A.N.; Qian, D.; Lam, J.S.; Ailles, L.E.; Wong, M.; et al. Association of reactive oxygen species levels and radioresistance in cancer stem cells. Nature 2009, 458, 780-783. [CrossRef]

22. Shi, X.; Zhang, Y.; Zheng, J.; Pan, J. Reactive oxygen species in cancer stem cells. Antioxid. Redox Signal. 2012, 16, 1215-1228. [CrossRef]

23. Kaur, P.; Johnson, A.; Northcote-Smith, J.; Lu, C.; Suntharalingam, K. Immunogenic Cell Death of Breast Cancer Stem Cells Induced by an Endoplasmic Reticulum-Targeting Copper(II) Complex. ChemBioChem 2020, 21, 3618-3624. [CrossRef] [PubMed]

24. Dhar, S.; Chakravarty, A.R. Efficient visible light induced nuclease activity of a ternary mono-1,10-phenanthroline copper(II) complex containing 2-(methylthio)ethylsalicylaldimine. Inorg. Chem. 2003, 42, 2483-2485. [CrossRef] [PubMed]

25. Reddy, P.A.; Santra, B.K.; Nethaji, M.; Chakravarty, A.R. Metal-assisted light-induced DNA cleavage activity of 2(methylthio)phenylsalicylaldimine Schiff base copper(II) complexes having planar heterocyclic bases. J. Inorg. Biochem. 2004, 98, 377-386. [CrossRef] [PubMed]

26. Waring, M.J. Lipophilicity in drug discovery. Expert Opin. Drug Discov. 2010, 5, 235-248. [CrossRef] [PubMed] 
27. Eskandari, A.; Suntharalingam, K. A reactive oxygen species-generating, cancer stem cell-potent manganese(II) complex and its encapsulation into polymeric nanoparticles. Chem. Sci. 2019, 10, 7792-7800. [CrossRef] [PubMed]

28. Dontu, G.; Abdallah, W.M.; Foley, J.M.; Jackson, K.W.; Clarke, M.F.; Kawamura, M.J.; Wicha, M.S. In vitro propagation and transcriptional profiling of human mammary stem/progenitor cells. Genes Dev. 2003, 17. [CrossRef]

29. Sheldrick, G. SADABS: Program for Absorption Correction Using Area Detector Data; University of Göttingen: Göttingen, Germany, 1996.

30. Sheldrick, G. A short history of SHELX. Acta Cryst. Sect. A 2008, 64, 112-122. [CrossRef] [PubMed]

31. Sheldrick, G.M. Crystal structure refinement withSHELXL. Acta Crystallogr. Sect. C 2015, 71, 3-8. [CrossRef]

32. Dolomanov, O.V.; Bourhis, L.J.; Gildea, R.J.; Howard, J.A.K.; Puschmann, H. OLEX2: A complete structure solution, refinement and analysis program. J. Appl. Crystallogr. 2009, 42, 339-341. [CrossRef]

33. Farrugia, L.J. WinGXandORTEP for Windows: An update. J. Appl. Cryst. 2012, 45, 849-854. [CrossRef] 